\title{
Value of morphotyping for the characterization of Candida albicans clinical isolates
}

\author{
Giovanni M Giammanco/ ${ }^{+}$, Maria Manuel Lopes*, Roney S Coimbra**/++, \\ Sarina Pignato***, Patrick AD Grimont**, Francine Grimont**, Graciete Freitas*, \\ Giuseppe Giammanco***
}

\begin{abstract}
Dipartimento di Igiene e Microbiologia, Università di Palermo, via del Vespro 133, I-90127 Palermo, Italia *Departamento de Microbiologia, Faculdade de Farmácia, Universidade de Lisboa, Lisboa, Portugal **Unité Biodiversité des Bactéries Pathogènes Emergentes, Unité INSERM 389, Institut Pasteur, Paris, France ***Dipartimento “G.F. Ingrassia” Igiene e Sanità Pubblica, Università di Catania, Catania, Italia
\end{abstract}

Until recently, morphotyping, a method evaluating fringe and surface characteristics of streak colonies grown on malt agar, has been recommended as a simple and unexpensive typing method for Candida albicans isolates. The discriminatory power and reproducibility of Hunter's modified scheme of Phongpaichit's morphotyping has been evaluated on $28 \mathrm{C}$. albicans isolates recovered from the oral cavity of asymptomatic human immunodeficiency viruspositive subjects, and compared to two molecular typing methods: randomly amplified polymorphic DNA (RAPD) fingerprinting, and contour clamped homogeneous electric field (CHEF) electrophoretic karyotyping. Morphological features of streak colonies allowed to distinguish 11 different morphotypes while RAPD fingerprinting yielded 25 different patterns and CHEF electrophoresis recognized 9 karyotypes. The discriminatory power calculated with the formula of Hunter and Gaston was 0.780 for morphotyping, 0.984 for RAPD fingerprinting, and 0.630 for karyotyping. Reproducibility was tested using 43 serial isolates from 15 subjects ( 2 to 6 isolates per subject) and by repeating the test after one year storage of the isolates. While genetic methods generally recognized a single type for all serial isolates from each of the subjects studied, morphotyping detected strain variations in five subjects in the absence of genetic confirmation. Poor reproducibility was demonstrated repeating morphotyping after one year storage of the isolates since differences in at least one character were detected in $92.9 \%$ of the strains.

Key words: Candida albicans - karyotyping - morphotyping - randomly amplified polymorphic DNA fingerprinting

Although different species of Candida, such as $C$. glabrata, C. tropicalis, C. krusei, and C. dubliniensis, are at present recognized as increasing opportunistic pathogens specially in human immunodeficiency virus (HIV) infected individuals and AIDS patients, C. albicans still remains the most common yeast isolated in humans (Anaissie 1992, Bart-Delabesse et al. 1993, Coleman et al. 1998, Sullivan et al. 2004). The different species of Candida can be identified by commercially available biochemical tests, but the characterization of isolates is necessary for epidemiological investigation and to ascertain if new candidiasis episodes are caused by relapse or due to reinfection. With this aim, a variety of molecular typing techniques has been used to distinguish Candida isolates, including multilocus enzyme electrophoresis, electrophoretic karyotyping, total genomic DNA restriction analysis, Southern blot hybridization with repetitive DNA probes, and randomly amplified polymorphic DNA analysis-RAPD (Magee \& Magee 1987, Bostock et al. 1993, Schonian et al. 1993, Clemons et al. 1997, Pujol et al. 1997, Taylor et al. 1999, Meyer et al. 2001).

\footnotetext{
${ }^{+}$Corresponding author. E-mail: g.m.giammanco@unipa.it

${ }^{++}$CNPq-Brazil fellowship

Received 4 January 2005

Accepted 27 April 2005
}

Electrophoretic karyotyping (EK) is a well-established method for typing Candida spp. (Monod et al. 1990). In particular, pulsed-field gel electrophoresis (PFGE) by contour clamped homogeneous electric field (CHEF) of $C$. albicans allows to subdivide this species in several karyotypes (Magee \& Magee 1987, Soll 2000) and to distinguish it from phenotypically close species like $C . d u$ bliniensis (Sullivan \& Coleman 1998, Giammanco et al. 2000). EK has been used to characterize strains of $C$. albicans responsible for recurrent oropharingeal candidiasis (Whelan et al. 1990, Schmid et al. 1992, BartDelabesse et al. 1993, Pfaller et al. 1994, Lupetti et al. 1995) and in epidemiological investigations to identify the sources of hospital acquired C. albicans infections (McNeil et al. 1999). Strain substitution or stable $C$. albicans colonization can be demonstrated by this method (Sangeorzan et al. 1994, Barton et al. 1995).

RAPD analysis or arbitrarily primed polymerase chain reaction (AP-PCR) analysis is technically simpler and often detects variation among Candida spp. isolates that are invariant with other typing methods (Taylor et al. 1999). The ability of RAPD fingerprinting to produce considerable DNA polymorphisms in Candida species prompted its application to the epidemiological analysis of related strains (Robert et al. 1995, Gyanchandani et al. 1998, Soll 2000). The reproducibility of RAPD analysis has been investigated by several authors (Tyler et al. 1997) and does not represent a problem if the technique is standardized. Unfortunately, molecular biology methods are often ex- 
pensive and technically demanding, and are not available in many routine clinical laboratories.

Conversely, phenotyping methods like auxonotyping, enzimotyping, or resistotyping do not need specialized equipment and are easy to perform. However, they all suffer from poor discriminatory power (Otero et al. 1995). Among phenotyping methods, Phongpaichit's morphotyping (Phongpaichit et al. 1987), a method evaluating fringe and surface characteristics of streak colonies grown on malt agar, has been shown in the past to have good discriminatory capacity (Otero et al. 1995). Hunter et al. (1989) modified the reading system in order to achieve better reproducibility and were able to relate strains of proven virulence with a distinct morphotype. This test is based on the evaluation of only four simple growth parameters such as fringe distribution, width, texture, and streak surface topography of linear colonies. However, concern has been expressed about the reproducibility of such a scheme, as $C$. albicans has been shown to undergo phenotypic switching (Slutsky et al. 1985). Highfrequency morphological variation not related to genomic DNA fingerprinting results has been demonstrated in recurrent isolates of C. albicans (O'Connell et al. 1995) and in conjunction with antifungal types alteration (Maffei et al. 1997).

Until recently, morphotyping has been recommended as a simple typing method to carry out in routine laboratories where other methods are impractical because of contraints of resources (Khan et al. 2003, Liguori et al. 2004), but its discriminatory power and reproducibility as a strain marker needs to be compared to molecular typing methods.

In the present study, a collection of unrelated clinical strains of C. albicans isolated from the oral cavity of 28 HIV-positive subjects (one strain per subject) was used in order to verify whether colony morphotyping according to Hunter's system (Hunter et al. 1989) could be a valuable typing method. Results have been compared with karyotyping and RAPD fingerprinting. The discriminatory power of the three typing methods was assessed calculating the numerical Index of Discrimination (ID) proposed by Hunter and Gaston (1988). Reproducibility was tested using 43 serial oropharyngeal isolates obtained from 15 asymptomatic HIV-positive subjects (2 to 6 isolates per subject) who had not undergone therapy with antimycotic drugs and were likely to harbour resident strains. To assess the stability of their morphological characters, 14 serial isolates were re-tested for morphotyping after one year storage in agar slants.

\section{MATERIALS AND METHODS}

Yeast strains - A collection of 28 clinical isolates of $C$. albicans was used for studying the discriminatory power of the typing methods. The collection consisted of consecutive clinical isolates (one per patient) obtained from oral swabs collected between January 1996 and December 1996 during one year of monitoring of HIV-positive subjects and submitted to the laboratory of the Istituto di Igiene e Medicina Preventiva of the University of Catania (Catania, Italy). Fifteen of the subjects under study were submitted to monthly oral sampling during the monitor- ing and a total of 43 serial isolates (two to six isolates per subject) were obtained. Serial isolates were used to assess the reproducibility of the typing. During all the monitoring period the subjects were asymptomatic for candidiasis and other opportunistic infections and were not treated with any antifungal drugs. Identification of isolates to species level was performed by the API ID $32 \mathrm{C}$ system (BioMérieux, Marcy-l'Etoile, France) and germtube formation in human serum. Strains were stored in Sabouraud agar slants for one year at room temperature before being re-tested for morphotyping.

RAPD fingerprinting - The DNA extraction was performed in accordance with Hoffman's protocol (1993). The single repeat sequence (GACA) $)_{4}$ was used as primer in the PCR experiments as described by Schonian et al. (1993). Briefly, $200 \mu \mathrm{M}$ of each deoxinucleotide (Amersham Pharmacia Biotech, Uppsala, Sweden), 16 pmol primer, 25 ng template DNA, 2.5 U Taq DNA polymerase (Perkin Elmer Corp., Applied Biosystems, New Jersey, US), $10 \mathrm{mM}$ Tris/ $\mathrm{HCl}$ (pH 8.3), $50 \mathrm{mM} \mathrm{KCl}, 1.5 \mathrm{mM} \mathrm{MgCl}_{2}$, and $3 \mathrm{mM}$ $\mathrm{Mg}$-acetate were added to a $50 \mu \mathrm{l}$ reaction volume. The cycle parameters were 33 cycles of $20 \mathrm{~s}$ at $94^{\circ} \mathrm{C}, 1 \mathrm{~min}$ at $43^{\circ} \mathrm{C}, 20 \mathrm{~s}$ at $72^{\circ} \mathrm{C}$, followed by a final extension cycle of 6 min at $72^{\circ} \mathrm{C}$, performed on a Hybaid thermocycler (Teddington Middlesex, UK). The RAPD products were separated by electrophoresis through a $1.2 \%$ agarose gel in $0.5 \times$ TBE ( $89 \mathrm{mM}$ Tris-borate, $2 \mathrm{mM}$ EDTA) buffer at 2 volts $/ \mathrm{cm}$ for $16 \mathrm{~h}$. The gels were stained with ethidium bromide and photographed. Lambda phage DNA digested with $B s t$ E II was used for the DNA fragments size determination. The Taxotron software (Taxolab Software, Institut Pasteur, Paris, France) compared the RAPD fingerprints and a distance coefficient was calculated using the complement of the Dice index. A dendrogram was drawn on the basis of the distance matrix generated by the unweighted pair group method of averages (UPGMA) algorithm.

$E K$ - C. albicans DNA for EK was prepared according to Monod et al. (1990). PFGE was performed in a CHEFDR III system (Bio-Rad Laboratories, Hercules, CA), using 0.8\% Pulsed-Field-Certified Agarose (Bio-Rad Laboratories) in TAE buffer (40 mM Tris-acetate; $1 \mathrm{mM}$ EDTA; $\mathrm{pH}$ 8.2). Two program blocks were used. For block one, switch time was $120 \mathrm{~s}$ and run time $24 \mathrm{~h}$. For block two, switch time was $240 \mathrm{~s}$ and run time $36 \mathrm{~h}$. Angle was fixed at $106^{\circ}$, gradient at 3.5 volts $/ \mathrm{cm}$, and temperature at $13^{\circ} \mathrm{C}$. Intact chromosomes from Saccharomyces cerevisiae strain YPH80 were used as molecular weight markers. Gels were stained in ethidium bromide. Gel images were electronically captured and karyotypes were analyzed by the Taxotron software (Taxolab Software, Institut Pasteur, Paris, France) as already described for RAPD fingerprints.

Morphotyping - Yeast cell suspensions were prepared and inoculated in duplicate on malt agar according to the method described by Phongpaichit et al. (1987). After incubation for 10 days at $28^{\circ} \mathrm{C}$ in the dark, morphological features of streak colonies were examined and each strain was assigned to a morphotype using the simplified four numbers code described by Hunter et al. (1989) based on fringe distribution, width, texture, and streak surface to- 
pography. The characters used to produce the morphotyping code are resumed in Table I. Morphotyping was repeated using the same protocol after one year storage of the strains in Sabouraud agar tubes.

Evaluation of the discriminatory power - In order to assess the discriminatory power of RAPD, karyotyping and morphotyping for the typing of C. albicans isolates, the numerical index of discrimination (ID) proposed by Hunter and Gaston (1988) has been calculated. This Index is based on the Simpson's index of diversity and is the result of the following equation:

$$
\mathrm{ID}=1-[1 / \mathrm{N}(\mathrm{N}-1)] \underset{\mathrm{j}=1}{\mathrm{~S}} \mathrm{nj}(\mathrm{nj}-1)
$$

where $\mathrm{N}$ is the total number of examined strains, $\mathrm{s}$ is the total number of types described, and $\mathrm{nj}$ is the number of strains belonging to the jth type.

\section{RESULTS}

Overall, the C. albicans isolates were indistinguishable by classical biochemical methods since they showed the same substrate assimilation profile corresponding to the API ID 32C code 73473400 15. Morphotyping, karyotyping and RAPD fingerprinting analysis results are resumed in Table II.

Analysis of the 28 isolates using RAPD fingerprinting with primer (GACA) ${ }_{4}$ originated 25 different amplification patterns (from R1 to R25) showing nine to 17 fragments of various intensity and ranging between 0.96 and $5.58 \mathrm{kbp}$ in size (Figs 1,2). Software analysis demonstrated that almost all the patients presented a specific RAPD profile. Only R2 pattern was shared by four patients.
EKs were determined by software analysis of the electrophoretic patterns revealing five to seven bands of different size. On the basis of the number and migration distances of DNA bands, nine different karyotypes (A to I) were recognized among the 28 isolates (Fig. 3). Type B karyotype was the most frequent (17 out of 28 isolates, $60.7 \%$ ), followed by type A (three isolates), type D (two isolates), and types C, E, F, G, H, and I (one isolate each). Eleven different morphotypes could be identified using the abbreviated code proposed by Hunter et al. (1989). Morphotype code 0000 was the most common (13 out of 28 isolates, $46.4 \%$ ), followed by $2240,2340,5240,7340$, and 7540 (two isolates each). Five other morphotypes (codes: 124 0, 324 0, 5340,7530 , and 754 6) were represented by one isolate each.

The discriminatory power of RAPD fingerprinting with primer $(\mathrm{GACA})_{4}$ calculated with the formula of Hunter and Gaston (1988) was 0.984. The ID was lower for karyotyping $(0.630)$ and for morphotyping $(0.780)$, with the larger typing cluster constituting $60.7 \%$ and $46.4 \%$ of the isolates, respectively (Table III). In both cases IDs were lower than the minimal index of 0.90 preconized as a desirable limit for results to be interpreted with confidence.

Results of the reproducibility test performed on serial isolates from 15 subjects are resumed in Table IV. With both RAPD fingerprinting and karyotyping, 41 isolates from 14 out of 15 subjects showed persistence of the same type throughout all of the monitoring period. Only in one subject (subject 8 ) the second isolate differed from the first one by all of the three typing methods suggesting a replacement of the resident strain in the oral cavity of the subject. Changes in the morphotyping codes of serial isolates that were not in agreement with the results of

TABLE I

Four digit morphotyping coding according to Hunter et al. (1989)

\begin{tabular}{lll}
\hline Feature & Code & Description \\
\hline Fringe & & \\
Distribution & 0 & Absent \\
& 1 & Discontinuous: $<20 \%$ of margin \\
& 2 & Discontinuous: $20-50 \%$ of margin \\
& 3 & Discontinuous: $50-90 \%$ of margin \\
Width & 5 & Continuous at periphery only or strands conspicuously fan shaped \\
& 7 & Continuous; filamentous outgrowths parallel \\
& 0 & Absent \\
Texture & 2 & $\leq 2$ mm \\
& 3 & $3-5$ mm \\
5 & $\geq 6$ mm \\
Streak surface topography & 0 & Absent \\
& 1 & Very coarse \\
& 2 & Coarse \\
& 3 & Intermediate \\
& 0 & Fine \\
& 1 & Smooth \\
& 2 & Nodular \\
& 4 & Pitted \\
& 5 & Crateriform \\
& 6 & Crateriform plus wrinkles or folds \\
& & Wrinkles or folds \\
& & Hairy \\
\hline
\end{tabular}


genotyping were detected in six subjects. In subject 15 three different morphotyping codes were found in the four genetically stable isolates collected over the four months monitoring. Two numerical codes (000 6 and 1340 ) that had not been encountered while typing the first 28 isolates were observed in serial isolates, bringing to 13 the total number of morphotypes encountered in this study.

Fourteen serial isolates from six subjects were re-tested for morphotyping after one year storage in Sabouraud agar tubes. Thirteen of the isolates $(92.9 \%)$ showed at least one difference in their morphotyping code after storage and six isolates differed for three or four figures.

\section{TABLE II}

Morphotypes, karyotypes, and randomly amplified polymorphic DNA (RAPD) fingerprinting typing for 28 clinical isolates of Candida albicans

\begin{tabular}{|c|c|c|c|}
\hline $\begin{array}{l}\text { Morphotype } \\
\text { code }^{a}\end{array}$ & $\begin{array}{l}\mathrm{Nr} \text { of } \\
\text { isolates }\end{array}$ & Karyotype (n) & RAPD type (n) \\
\hline 0000 & 13 & $\begin{array}{l}\text { A } \\
\text { B (8) }\end{array}$ & $\begin{array}{l}\text { R1 } \\
\text { R2 (4) } \\
\text { R4 } \\
\text { R7 } \\
\text { R8 } \\
\text { R25 } \\
\text { R3 } \\
\text { R5 } \\
\text { R13 } \\
\text { R23 }\end{array}$ \\
\hline 1240 & 1 & B & $\mathrm{R} 21$ \\
\hline 2240 & 2 & B (2) & $\begin{array}{l}\text { R17 } \\
\text { R19 }\end{array}$ \\
\hline 2340 & 2 & $\begin{array}{l}\mathrm{D} \\
\mathrm{H}\end{array}$ & $\begin{array}{l}\text { R18 } \\
\text { R20 }\end{array}$ \\
\hline 3240 & 1 & A & R6 \\
\hline 5240 & 2 & B (2) & $\begin{array}{l}\text { R10 } \\
\text { R15 }\end{array}$ \\
\hline 5340 & 1 & $\mathrm{E}$ & R9 \\
\hline 7340 & 2 & $\begin{array}{l}\mathrm{B} \\
\mathrm{F}\end{array}$ & $\begin{array}{l}\text { R14 } \\
\text { R12 }\end{array}$ \\
\hline 7530 & 1 & A & R16 \\
\hline 7540 & 2 & B (2) & $\begin{array}{l}\mathrm{R} 22 \\
\mathrm{R} 24\end{array}$ \\
\hline 7546 & 1 & $\mathrm{~B}$ & R11 \\
\hline
\end{tabular}

$a$ : based on fringe distribution, width, texture, and streak surface topography (Hunter et al. 1989).

\section{DISCUSSION}

The availability of a number of unrelated clinical isolates recovered during several months from the oral cavity of HIV-seropositive subjects gave us the opportunity to evaluate the usefulness of colony morphotyping on malt agar according to Hunter's scheme as an epidemiological typing method for $C$. albicans, by comparing this phenotypic typing method with DNA-based typing methods such as RAPD fingerprinting and karyotyping for the ability to discriminate among isolates.

Morphotyping is extremely simple and cheap to perform, requiring only malt agar plates. Moreover, special morphological markers, like discontinuous fringes, have been found to be associated with virulent strains and an increased risk of death in the case of deep infection (Hunter et al. 1989). Unfortunately, reproducibility of typing schemes based on colony morphology has already been reported to be affected by phenotypic variation (Slutsky et al. 1985), but a better in vitro reproducibility has been claimed for Hunter's scheme (Hunter et al. 1989, Otero et al. 1995). Hunter's scheme clusters Phongpaichit's morphotypes in a lower number, simplifying plates reading.

In our hands, the discriminatory capacity of this method, though lower than the 0.90 ID limit for results to be interpreted with confidence, was good compared to karyotyping. In fact, EK revealed a moderate variety of patterns among the isolates from different subjects. On the contrary, RAPD fingerprinting with the primer (GACA) $)_{4}$ showed a specific RAPD profile for each of the patients with the exception of a cluster of four isolates which produced identical patterns. Although we had no evidence of these isolates being epidemiologically linked, they were indistinguishable by all of the three typing methods used, since they also shared the same morphotype and karyotype.

Serial isolates belonging to the same subject which were likely to be the same strain have been used to assess reproducibility of typing results.

Reproducibility of the two genotyping methods was excellent, since for all but one patient they both assigned to a single type all of the serial isolates. On the contrary, in 6 out of 15 subjects with multiple isolates morphotypes variation not in agreement with genotyping were detected. In subject $\mathrm{nr} 15$ four genotypically identical serial isolates yielded three different morphotype codes, with the last isolate recovering the parental code. Poor reproducibility of morphotyping had already been signalled when recurrent isolates of $C$. albicans had been studied (O'Connell

TABLE III

Index of discrimination (ID) ${ }^{a}$ of typing methods used to discriminate among 28 Candida albicans strains

\begin{tabular}{lccc}
\hline Typing method & Nr of types & Size (\% of strains in largest cluster) & ID \\
\hline RAPD fingerprinting & 25 & 14.3 & 0.984 \\
Morphotyping & 11 & 46.4 & 0.780 \\
Karyotyping & 9 & 60.7 & 0.630
\end{tabular}

$a$ : according to Hunter and Gaston (1988). 


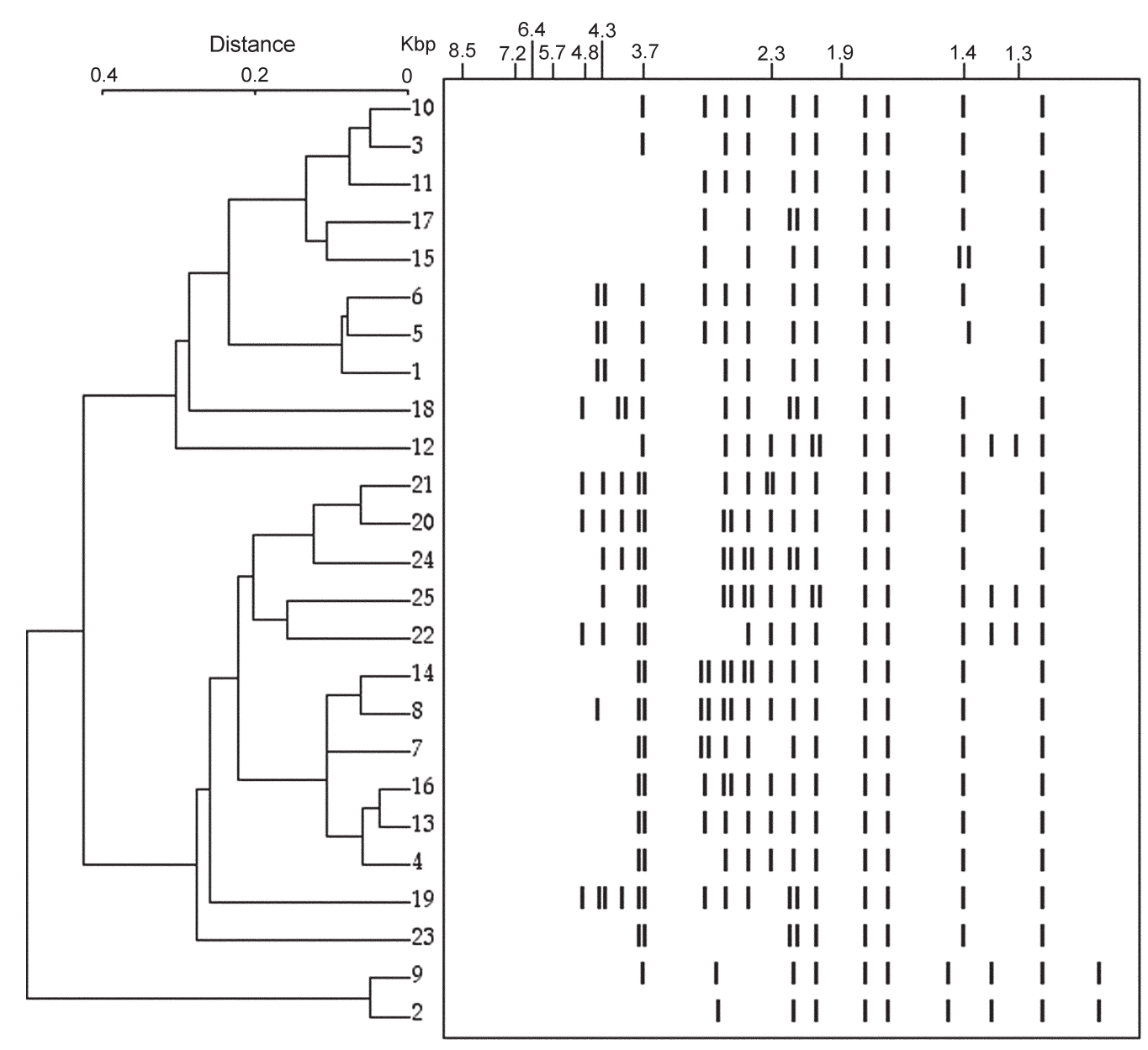

Fig. 1: dendrogram showing the genetic distance of the 25 (R1-R25) randomly amplified polymorphic DNA patterns obtained in this study with the primer $(\mathrm{GACA})_{4}$. The distance matrix was generated by using the complement of Dice similarity coefficient and the unweighted pair group method of averages (UPGMA) algorithm.

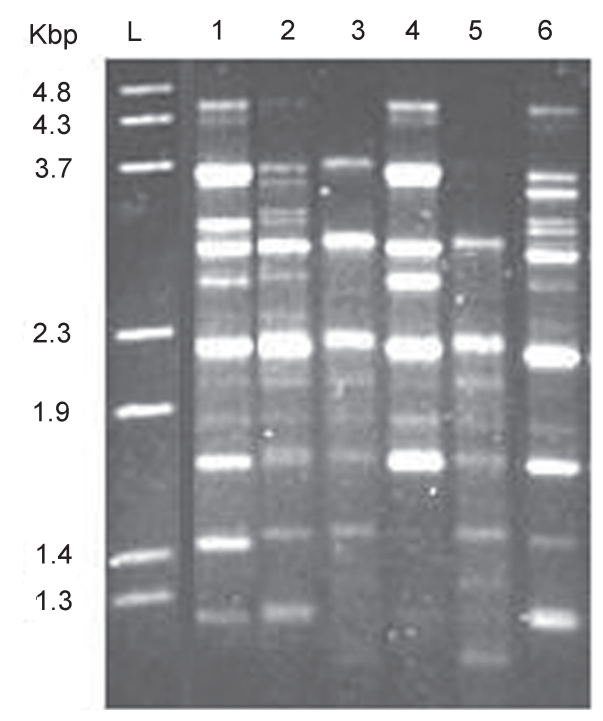

Fig. 2: randomly amplified polymorphic DNA patterns obtained with the primer $(\mathrm{GACA})_{4}$ for some of the Candida albicans isolates. Lanes - L: molecular weight marker (Lambda phage DNA BstEII digested); 1: R5 pattern; 2: R7 pattern; 3: R9 pattern; 4: R1 pattern; 5: R2 pattern; 6: R8 pattern. et al. 1995, Maffei et al. 1997) and phenotypic switching had been ascribed to selective pressure due to antifungal therapy (Maffei et al. 1997, Takasuka et al. 1998). In our study, phenotypic switching affecting morphological characters of colonies seems to have occurred even if none of our patients had been submitted to antifungal therapy.

A further reproducibility test performed after one year of storage in Sabouraud agar tubes revealed that all but one of fourteen serial isolates from six subjects showed at least one change in their morphotyping code. Differences in environmental conditions such as $\mathrm{pH}$ have already been demonstrated to affect the expression of several genes in C. albicans (De Bernardis et al. 1998). Therefore, growth conditions and time of harvesting, as well as modifications in the oral cavity environment, can compromise the reproducibility of biotyping methods such as morphotyping.

In conclusion, despite its good discriminatory capacity, low cost and ease of use, morphotyping is affected by low reproducibility. Reliability of this method in grouping isolates of $C$. albicans can not be guaranteed due to the risk of isolates exhibiting phenotypic switching. Therefore, we do not agree with the recommendation to use it 
in routine epidemiological investigations (Khan et al. 2003).

In accordance with previous reports (Bostock et al. 1993, Schonian et al. 1993, Holmberg \& Feroze 1996, Clemons et al. 1997, Pujol et al. 1997), RAPD analysis confirmed to be highly discriminatory and suitable for largescale epidemiological studies of $C$. albicans as well as for inquiries in epidemic outbreaks. In laboratories not equipped for molecular methods, isolates should be sent to reference laboratories for epidemiological studies.

Persistence of the same RAPD patterns in the serial isolates from oral cavities of several subjects, as observed in the present study, indicates that the same strain can be maintained for a long time in asymptomatic HIV-positive subjects.

TABLE IV

Randomly amplified polymorphic DNA (RAPD) fingerprinting patterns, karyotypes and morphotypes, of Candida albicans serial isolates

\begin{tabular}{|c|c|c|c|c|c|c|}
\hline Subject & Isolate & $\begin{array}{l}\text { Date of isolation } \\
\text { (day.mo.yr) }\end{array}$ & Karyotype & RAPD & $\begin{array}{l}\text { Morphotype } \\
\text { code }\end{array}$ & $\begin{array}{l}\text { Morphotype code } \\
\text { after } 1 \text { year storage }\end{array}$ \\
\hline \multirow[t]{2}{*}{6} & A & 24.01 .96 & B & $\mathrm{R} 4$ & 0000 & \\
\hline & B & 19.06 .96 & B & R4 & 0000 & \\
\hline \multirow[t]{2}{*}{7} & A & 16.09 .96 & B & $\mathrm{R} 2$ & 0000 & \\
\hline & B & 02.10 .96 & B & $\mathrm{R} 2$ & 0000 & \\
\hline \multirow[t]{2}{*}{8} & $\mathrm{D}$ & 28.06 .96 & A & R6 & 3240 & 7540 \\
\hline & $\mathrm{C}$ & 28.12 .96 & $\mathrm{C}$ & R5 & 5240 & 7540 \\
\hline \multirow[t]{3}{*}{10} & A & 10.01 .96 & $\mathrm{D}$ & $\mathrm{R} 5$ & 0000 & \\
\hline & B & 03.05 .96 & $\mathrm{D}$ & $\mathrm{R} 5$ & 0000 & \\
\hline & $\mathrm{C}$ & 12.07 .96 & $\mathrm{D}$ & R5 & 0006 & \\
\hline \multirow[t]{6}{*}{11} & A & 16.01 .96 & B & $\mathrm{R} 8$ & 0000 & \\
\hline & B & 21.02 .96 & B & $\mathrm{R} 8$ & 0000 & \\
\hline & $\mathrm{C}$ & 19.03 .96 & B & $\mathrm{R} 8$ & 0000 & \\
\hline & $\mathrm{D}$ & 28.06 .96 & $\mathrm{~B}$ & $\mathrm{R} 8$ & 0000 & \\
\hline & $\mathrm{E}$ & 16.11 .96 & B & $\mathrm{R} 8$ & 0000 & \\
\hline & $\mathrm{F}$ & 16.12 .96 & B & $\mathrm{R} 8$ & 0000 & \\
\hline \multirow[t]{2}{*}{12} & A & 31.01 .96 & E & R9 & 5340 & 7536 \\
\hline & B & 08.05 .96 & $\mathrm{E}$ & R9 & 7540 & 7522 \\
\hline \multirow[t]{3}{*}{13} & A & 10.01 .96 & B & $\mathrm{R} 10$ & 5240 & \\
\hline & B & 28.06 .96 & B & R10 & 5240 & \\
\hline & $\mathrm{C}$ & 28.12 .96 & B & $\mathrm{R} 10$ & 5240 & \\
\hline \multirow[t]{3}{*}{14} & A & 16.01 .96 & B & $\mathrm{R} 11$ & 7546 & \\
\hline & B & 15.05 .96 & B & $\mathrm{R} 11$ & 7546 & \\
\hline & $\mathrm{C}$ & 18.12 .96 & B & R11 & 7546 & \\
\hline \multirow[t]{4}{*}{15} & $\mathrm{~A}$ & 19.06 .96 & $\mathrm{~F}$ & $\mathrm{R} 12$ & 7340 & \\
\hline & B & 02.10 .96 & $\mathrm{~F}$ & $\mathrm{R} 12$ & 0000 & \\
\hline & $\mathrm{C}$ & 24.07 .96 & $\mathrm{~F}$ & $\mathrm{R} 12$ & 1340 & \\
\hline & $\mathrm{D}$ & 31.10 .96 & $\mathrm{~F}$ & R12 & 7340 & \\
\hline \multirow[t]{2}{*}{16} & A & 17.07 .96 & G & R13 & 0000 & 7340 \\
\hline & B & 27.12 .96 & G & $\mathrm{R} 13$ & 7340 & 7540 \\
\hline \multirow[t]{2}{*}{17} & A & 05.07 .96 & B & R14 & 7340 & 3340 \\
\hline & B & 08.12 .96 & B & R14 & 7340 & 7540 \\
\hline \multirow[t]{3}{*}{18} & A & 16.01 .96 & $\mathrm{~B}$ & $\mathrm{R} 15$ & 5240 & \\
\hline & B & 05.07 .96 & B & R15 & 5240 & \\
\hline & $\mathrm{C}$ & 31.10 .96 & B & $\mathrm{R} 15$ & 5240 & \\
\hline \multirow[t]{4}{*}{23} & A & 31.01 .96 & $\mathrm{H}$ & $\mathrm{R} 20$ & 2340 & 7530 \\
\hline & B & 21.02 .96 & $\mathrm{H}$ & $\mathrm{R} 20$ & 7540 & Unchanged \\
\hline & $\mathrm{C}$ & 28.06 .96 & $\mathrm{H}$ & $\mathrm{R} 20$ & 2340 & \\
\hline & $\mathrm{D}$ & 27.12 .96 & $\mathrm{H}$ & R20 & 2340 & 7342 \\
\hline \multirow[t]{3}{*}{24} & A & 21.06 .96 & B & $\mathrm{R} 21$ & 1240 & 5520 \\
\hline & B & 02.08 .96 & B & $\mathrm{R} 21$ & 1240 & 0000 \\
\hline & $\mathrm{C}$ & 09.10 .96 & B & R21 & 2240 & 7520 \\
\hline \multirow[t]{2}{*}{27} & $\mathrm{~A}$ & 27.01 .96 & B & $\mathrm{R} 24$ & 7540 & \\
\hline & B & 01.03 .96 & B & $\mathrm{R} 24$ & 7540 & \\
\hline
\end{tabular}




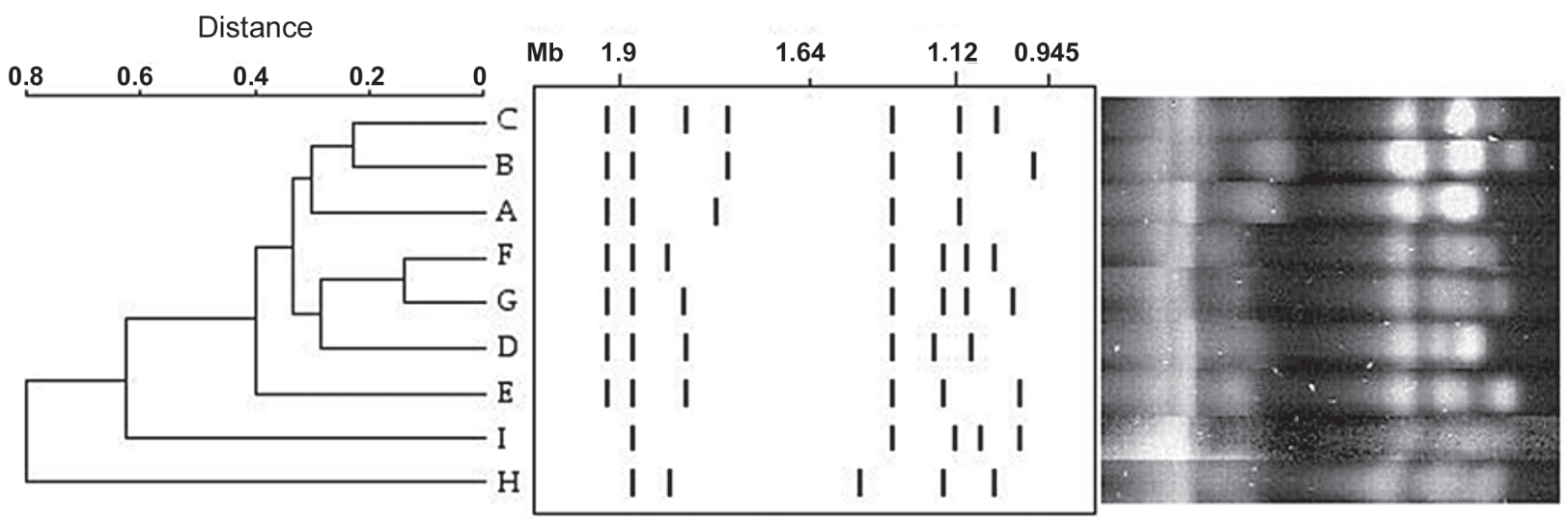

Fig. 3: images of agarose gel migrations and dendrogram showing the genetic distance of the nine (A-I) electrophoretic karyotyping (EK) patterns obtained in this study. The distance matrix was generated by using the complement of Dice similarity coefficient and the unweighted pair group method of averages (UPGMA) algorithm.

\section{REFERENCES}

Anaissie E 1992. Opportunistic mycoses in the immunocompromised host: experience at a cancer center and review. Clin Infect Dis 14 (Suppl. 1): S43-S53.

Bart-Delabesse E, Boiron P, Carlotti A, Dupont B 1993. Candida albicans genotyping in studies with patients with AIDS developing resistance to fluconazole. J Clin Microbiol 31: 2933-2937.

Barton RC, van Belkum A, Scherer S 1995. Stability of karyotype in serial isolates of Candida albicans from neutropenic patients. J Clin Microbiol 33: 794-796.

Bostock A, Khattak MN, Matthews R, Burnie J 1993. Comparation of PCR fingerprinting, by random amplification of polymorphic DNA, with other molecular typing methods for Candida albicans. J Gen Microbiol 139: 21792184.

Clemons KV, Feroze F, Holmberg K, Stevens DA 1997. Comparative analysis of genetic variability among Candida albicans isolates from different geographic locales by three genotypic methods. J Clin Microbiol 35: 1332-1336.

Coleman DC, Rinaldi MG, Haynes KA, Rex JH, Summerbell RC, Anaissie EJ, Li A, Sullivan DJ 1998. Importance of Candida species other than Candida albicans as opportunistic pathogens. Med Mycol 36 (Suppl. 1): 156-165.

De Bernardis F, Muhlschlegel FA, Cassone A, Fonzi WA 1998. The $\mathrm{pH}$ of host niche controls gene expression in and virulence of Candida albicans. Infect Immun 66: 3317-3325.

Giammanco GM, Pignato S, Salvo S, Giammanco G 2000. Carbohydrate assimilation profiles of the first Italian Candida dubliniensis clinical isolates recovered from an HIV-infected individual. Res Microbiol 151: 889-891.

Gyanchandani A, Khan ZK, Farooqui N, Goswani M, Ranade SA 1998. RAPD analysis of Candida albicans strains recovered from different immunocompromised patients (ICP) reveals an apparently non-random infectivity of the strains. Biochem Mol Int 44: 19-27.

Hoffman CS 1993. Preparation of yeast DNA, RNA and proteins. In FM Ausubel, R Brent, RE Kingston, DD Moore,
JG Seidman, JA Smith, K Struhl (eds), Current Protocols in Molecular Biology, John Wiley \& Sons, Inc., Hoboken, NJ, Vol. 2. Section 13.

Holmberg K, Feroze F 1996. Evaluation of an optimized system for random amplified polymorphic DNA (RAPD)analysis for genotypic mapping of Candida albicans strains. J Clin Lab Anal 10: 59-69.

Hunter PR, Fraser CAM, Mackenzie DWR 1989. Morphotype markers of virulence in human candidal infections. $J$ Med Microbiol 28: 85-91.

Hunter PR, Gaston MA 1988. Numerical index of the discriminatory ability of typing systems: an application of Simpson's index of diversity. J Clin Microbiol 26: 24652466.

Khan ZU, Chandy R, Metwali KE 2003. Candida albicans strain carriage in patients and nursing staff of an intensive care unit: a study of morphotypes and resistotypes. $M y$ coses 46: 479-486.

Liguori G, Marinelli A, Galdiero E, Arnese A, Di Onofrio V, Lucariello A, Marinelli P 2004. Candida spp. morphotype differentiation on Sabouraud-Triphenyltetrazolium-Agar (STTZ-Agar) under three different experimental conditions. New Microbiol 27: 193-197.

Lupetti A, Guzzi G, Paladini A, Swart K, Campa M, Senesi S 1995. Molecular typing of Candida albicans in oral candidiasis: kariotype epidemiology with human immunodeficiency virus-seropositive patients in comparison with that with healthy carriers. J Clin Microbiol 33: 1238-1242.

Maffei CM, Paula CR, Mazzocato TS, Franceschini S 1997. Phenotype and genotype of Candida albicans strains isolated from pregnant women with recurrent vaginitis. Mycopathologia 137: 87-94.

Magee BB, Magee PT 1987. Electrophoretic karyotypes and chromosome numbers in Candida species. J Gen Microbiol 133: 425-430.

McNeil MM, Lasker BA, Lott TJ, Jarvis WR 1999. Postsurgical Candida albicans infections associated with an extrinsically contaminated intravenous anesthetic agent. J Clin Microbiol 37: 1398-1403. 
Meunier JR, Grimont PAD 1993. Factors affecting reproducibility of random amplified polymorphic DNA fingerprinting. Res Microbiol 144: 373-379.

Meyer W, Maszewska K, Sorrell TC 2001. PCR fingerprinting: a convenient molecular tool to distinguish between Candida dubliniensis and Candida albicans. Med Mycol 39: 185-193.

Monod M, Porchet S, Baudraz-Rosselet F, Frenk E 1990. The identification of pathogenic yeast strains by electrophoretic analysis of their chromosomes. J Med Microbiol 29: 123129.

O’Connell B, Coleman DC, Bennett D, Sullivan D, McCann SR, Keane CT 1995. An epidemiological study of Candida species infection in cancer patients using genetic fingerprinting and morphotyping. J Hosp Infect 31: 211-217.

Otero L, Vazquez F, Palacio V, Vazquez S, Carreno F, Mendez FJ 1995. Comparison of seven phenotyping methods for Candida albicans. Eur J Epidemiol 11: 221-224.

Pfaller MA, Rhine-Chalberg J, Redding SW, Smith J, Farinacci G, Fothergill AW, Rinaldi MG 1994. Variations in fluconazole susceptibility and electrophoretic karyotype among oral isolates of Candida albicans from patients with AIDS and oral candidiasis. J Clin Microbiol 32: 59-64.

Phongpaichit S, Mackenzie DWR, Fraser C 1987. Strain differentiation of Candida albicans by morphotyping. Epid Infect 99: 421-428.

Pujol C, Joly S, Lockhart SR, Noel S, Tibayrenc M, Soll DR 1997. Parity among the randomly amplified polymorphic DNA method, multilocus enzyme electrophoresis, and Southern blot hybridization with the moderately repetitive DNA probe $\mathrm{Ca} 3$ for fingerprinting Candida albicans. J Clin Microbiol 35: 2348-2358.

Robert F, Lebreton F, Bougnoux ME, Paugam A, Wassermann D, Schlotterer M, Tourte-Schaefer C, Dupouy-Camet J 1995. Use of random amplified polymorphic DNA as a typing method for Candida albicans in epidemiological surveillance of a burn unit. J Clin Microbiol 33: 2366-2371.

Sangeorzan JA, Bradley SF, He X, Zarins LT, Ridenour GL, Tiballi RN, Kauffman CA 1994. Epidemiology of oral candidiasis in HIV-infected patients: colonization, infection, treatment, and emergence of fluconazole resistance. Am J Med 97: 339-346.

Schmid J, Odds FC, Wiselka MJ, Nicholson KG, Soll DR 1992. Genetic similarity and maintenance of Candida albicans strains from a group of AIDS patients, demonstrated by DNA fingerprinting. J Clin Microbiol 30: 935-941.

Schonian G, Meusel O, Tietz HJ, Meyer W, Graser Y, Tausch I, Presber W, Mitchell TG 1993. Identification of clinical strains of Candida albicans by DNA fingerprinting with the polymerase chain reaction. Mycoses 36: 171-179.

Slutsky B, Buffo J, Soll DR 1985. High-frequency switching of colony morphology in Candida albicans. Science 230: 666-669.

Soll DR 2000. The ins and outs of DNA fingerprinting the infectious fungi. Clin Microbiol Rev 13: 332-370.

Sullivan D, Coleman D 1998. Candida dubliniensis: characteristics and identification. J Clin Microbiol 36: 329-334.

Sullivan D, Moran GP, Pinjon E, Al-Mosaid A, Stokes C, Vaughan C, Coleman DC 2004. Comparison of the epidemiology, drug resistance mechanisms, and virulence of Candida dubliniensis and Candida albicans. FEMS Yeast Res 4: 369-376.

Takasuka T, Baily GG, Birch M, Anderson MJ, Law D, Denning DW 1998. Variation in morphotype, karyotype and DNA type of fluconazole resistant Candida albicans from an AIDS patient. $J$ Infect 36: 57-62.

Taylor JW, Geiser DM, Burt A, Koufopanou V 1999. The evolutionary biology and population genetics underlying fungal strain typing. Clin Microbiol Rev 12: 126-146.

Tyler KD, Wang G, Tyler SD, Johnson WM 1997. Factors affecting reliability and reproducibility of amplificationbased DNA fingerprinting of representative bacterial pathogens. J Clin Microbiol 35: 339-346.

Whelan WL, Kirsch DR, Kwon-Chung KJ, Wahl SM, Smith PD 1990. Candida albicans in patients with the acquired immunodeficiency syndrome: absence of a novel or hypervirulent strain. J Infect Dis 162: 513-518. 